\title{
Developing New Educational Frontiers through Breakthroughs in Cognitive Computation and New Dimensions in Pedagogical Technology
}

\author{
J. C. Olabe, X. Basogain, and M. A. Olabe
}

\begin{abstract}
The world of higher education is being transformed by three forces addressing three fundamental aspects of education: access to high quality education; models for how the mind works, and what its capabilities and limitations are; and the use of technology for the implementation of pedagogical strategies that will lead to optimal learning experiences. This article reviews: some of the major changes is online access to higher education around the world; the fundamental ideas that cognitive sciences and computation are advancing for a new educational system; and a set of specific examples where this access and these methodologies are being implemented in the real world.
\end{abstract}

Index Terms-Computational thinking, online education, cognitive sciences, lifelong learning teaching.

\section{ONLINE ACCESS TO HighER EDUCATION}

Our research team has focused its teaching and research activities of the last decade in the area of technology and e-learning in higher education. The team was able to analyze, experiment with, and implement systematic studies of courses offered in these platforms. The first section of this paper describes our analysis of the implications of MOOC platforms and their potential impact in the future model of Universities as they expand to new geographic areas and new demographic groups.

\section{A. MOOCs}

The three large MOOC platforms, Coursera [1], edX [2], and Udacity [3], are based in the United States, although Coursera and edX are lately promoting an international and multilingual presence of its partner universities. The comparative study of these three platforms [4] highlights the similarities and differences in their profiles, course structure, assessment tools, academic integrity, social interaction, pacing, as well as certificates and course credit offerings.

The Coursera platform currently includes a consortium of 140 educational partners from 30 countries including Stanford, Princeton, and Johns Hopkins in the US, The University of Edinburgh and Ecole Polytechnique Fédérale de Lausanne in Europe, or the Chinese University of Hong

Manuscript received December 10, 2015; revised February 20, 2016. This work was supported in part by the Research Development Grants of the University Basque System (2013-15), Department of Education, Universities and Research - Basque Government, Spain.

J. C. Olabe is with the Christian Brothers University (CBU), Memphis, USA (e-mail: jolabe@cbu.edu).

$\mathrm{X}$. Basogain and M. A. Olabe are with the University of the Basque Country, Euskal Herriko Unibertsitatea (UPV/EHU), Spain (e-mail xabier.basogain@ehu.eus, miguelangel.olabe@ehu.eus).
Kong. The platform edX was founded in 2012 by MIT and Harvard, includes courses from over 60 institutions such as the University of Toronto, Australian National University, and Delft University of Technology among other international institutions. The third platform in the group, Udacity, was created by Sebastian Thrun and Peter Norvig from Stanford after their successful online course "Introduction to Artificial Intelligence" launched in October of 2011 [5].

In Ibero-America's Higher Education, the platform Miríada X ranks at the top of these portals. This platform is committed to promoting open knowledge, and to allow it to be transmitted and enriched via the Internet. The platform is designed to teach courses as MOOC platforms [6].

The MOOC phenomenon is reshaping the world of online education [7]. The number of registered students in Coursera is increasing rapidly. After being created in the spring of 2012, it reached the milestone of 1 million students in August of 2012. In January of 2013 it arrived at 2 million students, and in May of 2013 it surpassed 3.5 million students from over 200 countries. In December of 2015 reached 16,5 million students. This impressive growth surpasses the most optimistic expectations. The MOOC phenomenon is experiencing a fast and wide expansion, with characteristics that are superior to other social phenomena such as Facebook.

Signs of the relevance of MOOCs in education can be found in the portal Europe Open Education. This European Commission portal provides users since September 2013 open educational resources in Europe. The section 'find' in this website is divided into the sections MOOCs, courses and open educational resources. The MOOCs finder allows the search by subject and by language. The Open Education Scoreboard tool compiles European and non-European MOOCs, and highlights the huge potential that the European institutions have in the world of MOOCs [8].

\section{B. Courses}

The MOOC platforms described earlier present a set of common characteristics. Founded in the late 2011 or early 2012 , they began by offering only a limited set of courses. This small set of courses is being continually augmented, with various levels of growth, adding not only courses in the same topic areas, such as computer science, but also expanding the taxonomy of higher education areas of study, such as social science, humanities, or education. Coursera and edX also pursue a policy of enlarging the community of universities participating in their projects.

The first courses offered were in general in technology 
related areas, such as computer science, perhaps given the background of their founders. But with time the number and scope of materials has increased exponentially. Coursera, for example, in December of 2015 it offers over 1,300 courses in more than twenty-five areas such as arts, biology, business, chemistry, economics, education, engineering, humanities, law, mathematics, medicine, music, physics or social sciences. The number of courses and areas is expected to continue growing.

This wide scope of course categories found in current MOOCs is relevant, since its addresses the critical issue of whether the online platforms of education are only suitable for areas in the fields of sciences and engineering. Social sciences and humanities also have found a valid platform in the world of MOOCs. An early example of such courses is the course "Introduction to Sociology," by Mitchell Duneier of Princeton University. Professor Duneier experimented with adapting his teaching style in the traditional classroom to an online audience of tenths of thousands of students [9].

These institutions started with offerings from two to four university partners. But in the following months, as a policy of enlarging the number of university patterns seemed to be in place, the number of courses increased proportionally. Although the policy of increasing university partners may continue for a short period, the goal seems to be obtaining an optimal consortium size: not too small as to limit the consortium potential; and not too large as to devaluate the perceived quality of their offerings.

From January 2013 until December 2015, there have been more than one million and three hundred thousand students registered in Miríada X, including 230 courses taught by forty nine universities from 10 countries.

The courses offered in these platforms have been systematically designed and implemented with a common design pattern. Each course includes a set of components accessible via the main menu allowing an efficient navigation The common elements include: Syllabus, Video Lectures, Homework Quizzes, Written Assignments, Final Exam, Discussion Forums, Course Wiki, Peer Assessments, Course Logistics, and Students survey.

The course interface is based on a simple design. The links to each component of the course include the corresponding information to the learning resource. The educational materials are accessible through streaming or by direct download. The student can download to her/his own computer all the video lectures, the transcripts of these videos, the course supporting materials, such as power points, journal articles, graphics, etc.

The student's progress throughout the course is provided in several forms: the video lectures already completed are labeled electronically with a visual mark, and the assignments and quizzes are listed with a summary of the achieved results and corresponding grades. These services foster a better self-monitoring on the part of the student, and it is an invaluable tool to help students manage their time and effort.

Before registering in a new course, the students have access to all relevant information about the course. This information includes data regarding the professor of the class, syllabus, class format, frequently asked questions, and an introductory video describing the course. Currently the registration is free, and requires only providing a name and electronic mail. This process is immediate, and the student gains direct access to the course and all its components. After registering in one course, the student is free to explore other proposed courses and continue further registrations.

\section{Research and Experimentation}

The fairly recent arrival of MOOC platforms has been the consequence of several factors. One factor is the correct combination of new technologies and new pedagogical methodologies in the world of online education. The implementation of operational MOOC platforms is the result of multiple research activities, mainly in the university environment, dedicated to the advancement of effective online education. The research groups working in these areas have developed and tested new pedagogical methodologies in order to address the challenges of massive (thousands of students in a course) open online courses. The pedagogical foundations of these platforms are based on concrete work and projects developed by researchers in the area of massive learning that is both efficient and provides good performance evaluations of students.

The implementation and experimentation period for these platforms is still open. Currently the profile of these three platforms is centered on semi-traditional methods of content delivery and student evaluation. This approach is not final. The experimentation resulting from the delivery of MOOC courses is providing input for the improvement of the models. There is a debate about the characteristics of a true MOOC, leading to suggestions that they need to be classified as either cMOOCs or XMOOCs [10]. The goal of MOOCs is to offer the best learning experience, and MOOC platform designers continue their quest to improve their results.

An example is the course that a team of professors and researchers associated with the MSc in E-Learning of The University of Edinburgh offered in Coursera. The title of the course is "E-learning and digital cultures." Their own design of the course includes innovative practices that have emerged directly from the world of online education and that perhaps conflict with some of the criteria of the current MOOCs. For example, in this course it is more important to give priority to the students' community and the learning networks than to the task of providing content. The course also explores methods of evaluation, such as digital and multimodal assignments, and group assignments [11].

Another example of research and experimentation on technology and methodology is the use of the tool Hangout of Google Plus. Professor Mitchell Duneier [12] first used this tool in his course "Introduction to Sociology." The tool allowed the implementation of real time debates with 8 students from around the world. The debate could be followed live by the thousands of registered students in the course. Later the debate was archived and posted in the course site, allowing its viewing at any later time. Other equivalent tools allow for similar office hours services to the students.

Another example that illustrates how the process of further defining MOOCs is evolving is the course "Fundamentals of Online Education: Planning and Application." This course 
had to be suspended during its first week of delivery due to technical and management problems. The technical problems were related to the use of Google Drive in the process of registering students in the discussion forums. Google Drive had a limit of 50 simultaneous editors in their spreadsheets for these groups. Clearly Google Drive was not the best choice for this course where more than 40,000 students were registered. The management problems were manifest when very little response was given when the problem was first reported by the students, and confusing and ambiguous information was provided. In the section of lessons learned in this experience we can find a checklist of situations and decisions to avoid.

Research in the area of MOOCs is being pursued in multiple fronts. One of them is the technological needs to host MOOCs. Google offered, under an open source project called Course Builder, a platform for hosting MOOCs. Google used this technology in its own first MOOC called Power Searching with Google, delivered in July 2012 by Dan Russell. Over 155K students [13] registered for the course. Stanford University is offering its platform Class2Go [14].

In the near future the world of higher education will continue experimenting with technologies, pedagogical methods, new services, and new tools. It is early to predict the characteristics of these platforms as they will exist in a few years, but there is a clear commitment on the part of university administrators, faculty and students, to explore alternatives to the economic and pedagogical model of current higher education. The goal of this chapter has been to identify and highlight the main forces behind this movement, the potential obstacles to its implementation, the roles of its participants, and the consequences of its development.

\section{Pedagogical Technology}

\section{A. Learning Activities}

The main goal of MOOCs in the design of their courses is to help the student attain mastery of their content. With this purpose, MOOCs implement a series of protocols and activities with new approaches to online education. The activities are integrated throughout the continued progress of the course. These activities are student-centered, and the professor plays a supporting role in the task of achieving content mastery on the part of the student.

The concept of Flipping the Class consists in interchanging the places where the students traditionally participate in learning activities. The traditional lecture activity with the professor now will take place in the privacy of the student home or residency. The activities of working homework problems will now take place in the classroom or in forums in direct collaboration with the teacher and fellow students. In some course implementations, the student participates in synchronous events of group tutoring and group debates on the studied materials.

The advantages of this new distribution of activities are several. The student views the lectures and learns according to her/his own rhythm and preferences. The student has individual access and control over the video lectures to study them as many times as needed. The students' participation in forums and debates allows them to learn about the work of other students. This approach of sharing homework activities with other classmates increases the students' knowledge and perspective on the subject. These activities are not new in the world of online education using Learning Management Systems (LMS). But it has been the arrival of MOOCs that has allowed the materialization in and efficient and effective way of Flipping the Class.

The monitoring and communication of the learning progress of students constitutes another fundamental component of MOOCs. Students have access to several sources of information on their progress in the course. These sources provide a valuable feedback for the student, creating a great potential for motivation and encouragement to maintain the study plans required to successfully complete the course. The first form of feedback is the response to the quizzes integrated within the video lectures. The success or lack thereof in the quiz will guide the student to continue with the lessons or to review until the content is mastered. The second form of feedback is provided as a response to the assignments.

Throughout the course, the students participate in a continuous evaluation process that includes assignment projects. These assignments are designed to measure and inform the student of her/his level of mastery of the course content. The student uses this tool of formative evaluation to reinforce her/his learning attitude. These activities of evaluation are based on a continuous interaction between the student, the professor and the other students in the course, and provide guidance and motivation throughout the course. Students abandon a passive role in the course for the benefit of a more active and protagonist role.

The process of peer review is another important component in MOOCs. In this process the task of the students in to evaluate and comment the work of a group of fellow students. One of the goals of this activity is to manage the time consuming task of evaluating and grading the assignments and work implemented by the thousands of students participating in the MOOCs. The instructors of the class provide a solution guide and a protocol for the process of peer review. In this new activity the student participates actively in the role of instructor or teaching assistant, providing an invaluable experience and requiring a level of preparation and responsibility rarely available to students. The students' way of thinking, analyze and organize their knowledge on the subject reaches a new dimension of critical and reflexive analysis.

MOOCs also provide means to acknowledge the work and achievements of the student throughout the course. This acknowledgment can be materialized in the form of a certificate. The certificate indicates that the student has completed the course. This certificate will have official status if the student pays a fee and completes a proctored exam. Otherwise the certificate has a more informal status, similar to a badge of participation.

The students acknowledge at the beginning of the course, through the process of registration, the adherence to an honor code related to the authenticity of the work submitted and the identity of the sender. Students that have completed the course assignments and obtain the required grade 
qualifications, receive a corresponding certificate. The advantages of this type of acknowledgments are several, among them the increased motivation of the students to participate and complete the course, as well as the possibility that credit might eventually be transferred to universities, and therefore count towards a formal degree [15].

\section{B. Video Lectures}

An innovative and fundamental element of the current generation of MOOCs is the implementation and conceptual format of the video lectures. The innovation resides in the new philosophy behind the creation of the video segments where the professor communicates the core content of the course to the students. In the past, the resource of video lectures used in online education with streaming technology has helped the distribution of content over the network. Video technology, as an academic resource has provided significant benefits in the teaching-learning process over the Internet. However the potential of video lectures in the world of online education has not been completely developed for multiple reasons. One of the critical reasons is that the reproduction of the traditional lecture in the classroom by recording it and then transmitting it via the network is not an effective teaching tool.

The video lectures of the current MOOCs are based on a different philosophy and conceptual approach. These videos are relatively short (5-10 minutes). Each video focuses on the study of an identifiably goal in a way that is simple and clear. To achieve this goal, a phase of detailed planning is required on the part of the professor.

In addition, an extensive post production completes the process. The professor presents the content in her/his office, in a traditional classroom, or in a special studio. Often the professor is aided by a graphic tablet that supports the explanations and uses computer based applications to illustrate important elements of the lecture. The process of post-production manipulates the recorded material in order to optimize its didactic value and quality. These processes include the elimination of undesired segments, reduction of the viewing time by speeding slow periods, such as writing and drawing, image and sound processing, integration of multiple video sources, for example the professor and the computer, overlay of graphic and textual information, etc.

The innovation of these video lectures resides not only in the technical and quality improvements and optimizations but also in the added value that the professor integrates in their content. The innovation also includes the integration of quizzes as an essential element of the video lecture. This integration of brief, multiple-choice questions has the goal of self-assessment on the part of the student. This method uses a traditional tool in a new environment and with a new purpose.

The student must correctly respond to the sequence of short quizzes integrated in the video lecture in order to proceed ahead. Each response submitted by the student provides her/him with feedback on her/his progress and auto evaluation of the level of understanding, reinforcing the learning process. The continued exercise of accessing the knowledge recently acquired provided by the quizzes stimulates learning activities not present in other didactic methodologies [16].

The experience of the student viewing these new MOOC video lectures is different from that of viewing a traditional online video. The student has direct access to a comprehensive set of video segments for each lecture. These videos are organized by lecture, by weekly assignments, and by course units. The course content is organized in sets of short videos designed to be viewed sequentially, where individual concepts, tools and ideas are progressively introduced and practiced. The student is aware that the professor in introducing a new concept in each video, and that at its conclusion the student is expected to respond to one or several questions intended to evaluate the degree in which this new knowledge has been acquired.

This expectation generates a new attitude of the student as she/he views the lectures. It is not a passive attitude of a student sitting at end of a large lecture hall, without direct and personal contact with the instructor, but rather a motivated attitude of a student in direct dialog with her/his own professor. Student and professor establish a cooperative dynamic of collaboration and knowledge transfer. The student is motivated to correctly answer the questions at the end of each video segment.

A one to one relationship is established between the student and her/his professor. When the professor introduces a new concept the student actively participates, and when the professor ask questions, the student reflects and answers, and receives feedback on her/his progress. Instructional methods designed for large groups of students can be designed to be based on one to one tutoring methodologies [17].

\section{Cognitive COMPUTING}

During the last few decades there had been numerous advances [18-26] in the areas of cognitive science, neuroscience and computation that suggest that both the content and teaching methodology used in K-12 education should be redesigned. In this paper, the results of an experiment are described, showing how some of new these ideas could be integrated into the classroom and what their impact might be

Our research team collaborates with schools around the world in the area of Computational Thinking. This work is done with public schools systems (mostly in the developing world), and with private school systems (mostly in the developed world). The governments of the developing world see Computational Thinking as their best chance to close the gap in their education systems, and the developed world sees Computational Thinking as the cornerstone of a technological society.

England is the first major developed country to formally integrate into its public school system the subject of computation - the concept that supports the development of Computational Thinking. Beginning in Kindergarten and going through high school, children and young adults in England live the world of Computational Thinking every day.

So, what is Computational Thinking? Why does it seem to attract such diverse attention, and what can it bring us that we don't already have? 


\section{A. Heuristic Search}

First an introduction to the workhorse of our so-called rational mind: the heuristic search. We think we are rational, but for the most part we are not. There are good evolutionary reasons why we could not survive with a reasoning mind-reasoning is slow, costly, and unreliable. The human species survived and prospered because it developed a decision-making process that was fast, inexpensive, and if not completely reliable, always favoring the safe response.

S1: All professors are vain; some non-vain people don't drink coffee; therefore some professors drink coffee.

Sentence S1 is a simple argument with two premises and one conclusion. Computationally it is extremely simple, but many of us find it convoluted and taxing to our energy and patience. We certainly don't yearn spending an afternoon playing that game.

S2: The old banker and his wife bumped into his young mistress.

Sentence S2 is computationally much more complex than S1, however our mind has computed effortlessly, automatically, immediately (and unavoidably) large sets of data, feelings, desires, reactions, and moods.

In 2002, psychologist Daniel Kahneman was awarded the Nobel Prize in Economics for a simple, profound, and consequential idea: a) When we make decisions we think we reason, but we don't, we instead use heuristics; and b) these heuristics are often biased and lead us to error.

The reasons why we use heuristics were listed before. Why, however, we think we reason instead is perhaps a cognitive trap. To have an accurate model of the mind, our computational machine, is the first step in designing a productive educational system.

\section{B. Type-A Problems}

Type-A problems are such an important set of problems that they deserve a name (perhaps a more descriptive name) and also a monument. A monument not because we admire them, rather because it will remind us of the past and will make us reflects about the future.

During the K-12 years, Type-A problems are all that is done in Math and Sciences classes. We may have the impression that those long years cover a vast set of topics, but the reality is that it is only a variation on a single theme: how to solve Type-A problems. A Type-A problem consists of three phases: 1) Data: We are given a set of known data and unknown data, and we have to identify them. 2) Rules: There are rules that relate these data, and it is up to us to know them or to find them. 3) Result: We need to untangle the data attached to these rules and obtain the final result (this often requires algebra and almost always arithmetic).

Type-A problems require for their resolution the activation of a set of cognitive processes known as System-2, which involves attention. System-2 tires soon, and it interferes, which means that no other task can be implemented at the same time. A surgeon would have to pause her open heart surgery, close her eyes, and deeply concentrate to correctly multiply 27 x 34 in her mind, if the life of her patient would depend on a correct answer. That is a precarious system; a waste of the human capacities and training time.

\section{Computational Thinking}

Each day we know more about how the mind works. What it can do and what it should not waste time trying to solve. Computational Thinking is the set of fundamental ideas, derived from cognitive sciences and computation, as well as epistemology, with two main goals: 1) Discover the uncharted world of cognitive processes that the human mind can sustain, provided the required tools; and 2) Develop a set of experiences that will allow students acquire these tools, engage in these cognitive processes, and produce rich and innovative results.

\section{Language and the Chinese Room}

Ideas are supported in language, and complex ideas require languages that support complex ideas. Natural languages-English, Spanish, etc.-are a miracle of evolution, and indeed allow for complex ideas, but as we saw earlier with sentences S1 and S2, they seem to work unevenly in different environments and soon find a limiting ceiling. Complex ideas require languages that support complex ideas.

A language for representing complex ideas is based on a simple set of three mechanisms: 1) a set of primitives that we start with; 2) a means of combining these primitives; and 3) [this is the breakthrough that natural languages did not evolve to implement well] a means of abstraction by which we name the complex idea, and from now on it becomes a new primitive from which higher level ideas will be created. This is the root of Emergence.

The Chinese Room thought experiment deals with the concept of whether a computer can think and have cognitive states, as humans do. For the untrained mind this is a very difficult problem because we don't know what the mind is, and we don't know what a computer is. Some cognitive traps may supply some persuasive opinions, nonetheless unsupported.

Philosophy and Psychology classes studying this problem start by first teaching students a language that supports the ideas of a Turing machine or a Von Neumann machine and how they operate (Engineering freshmen also learn this language, although with less philosophical objectives). This language provides the primitives to entertain in their minds models about their minds, and models about computers.

It also allows students to entertain in their minds the fundamental idea of Emergence, how intelligence can emerge from non-intelligent devices (this is where the fundamental difficulty of the Chinese Room problem resides.) A NAND gate is an electronic device with two inputs. One output is always one, except when both inputs are one; at that time, the output turns to zero. Out of this simple, mindless, unintelligent device all the data and all computation in the world is born.

Equipped with an appropriate language, the mystery that plagued philosophy classes for decades (and still does in some universities) has been downgraded to a simple problem that every student confidently solves. This is Computational Thinking.

\section{E. Computational Curriculum}

Thinking provides the path to higher cognitive lives for our students and ourselves, but the path needs to be created. 
Students need to be immersed in the world where this language is spoken and where they can work with others and explore new ideas. It is similar to going to China for one year, getting integrated in Chinese society, learning their language and customs and culture and food and music by being with them and interacting with them.

The world of Computational Thinking is now being created by many research groups. It begins with the creation of curriculum - the activities that our children and young students will experience in their school life during their formative years.

This work includes innumerable fields. Our research team has been working for the last decade in areas such as Vector Differential Geometry (also known as the art of beautiful geometry), Cybernetics (the art and science of self-controlled organisms, such as butterflies and self-driving cars), Story Telling (the art of narrative self-expression), Discrete Calculus (the art of the moving universe), and others.

A simple example will illustrate the word on Discrete Calculus and the art of the moving universe. Long ago, Galileo concluded that a ball rolls down a ramp with a velocity that he described as the Law of the Odd Numbers (such as $1,3,5,7,9, \ldots$ ). That is probably one of the most beautiful laws in the universe. In fact, it rules the motion of all planets, stars, and galaxies in the universe. Later, Newton noticed that when subtracting the odd numbers the difference between them was constant $(3-1=2,5-3=2,7-5=2)$ and that is the constant acceleration of the gravitational field. He also noticed that the cumulative sum was $(1+3=4, . .+5=9, .+7=16$. $+9=25 \ldots)$ a set of square numbers: a parabola that describes the path of falling body.

This insight is not lost in a ten-year-old child, who soon creates a bouncing ball ruled by the Law of the Odd Numbers, which bounces like her basketball when she plays with her friends at recess. The formal name of the system that the child has created is a second order discrete differential equation system. This creation moves the ball as if it were in the presence of a real gravitational field. As the child plays with her creation, one day she notices that in the presence of an unexpected obstacle - a table, for example - the ball knows how high to bounce. Then she asks herself, "What is inside the Law of the Odd Numbers, which is the only thing the ball knows, that allows it know how high to bounce, regardless of the location of the obstacle?" The answer comes to her in less than one hour. This is Computational Thinking.

These students live their school day in a cognitive world that is far from the unnecessarily fruitless and unnecessarily unpleasant world of convention.

\section{Case Study: Course Computational Thinking IN THE SCHOOLS}

This section describes some of the features of a MOOC implemented by the authors in the platform Miríada X. The course, Computational Thinking in Schools, has been offered twice in the academic year 2015, and over 4,000 students of 35 countries have participated in each edition. The course implements the fundamental principles of Mastery Learning, and it has at its subject topic the integration in the classroom of the ideas and practices of Computational Thinking.

\section{A. Context}

The formal study of computational skills in primary and secondary schools has been recognized by many institutions and administrations. For example England, beginning the academic year 2014-15, has formally included the study of computational thinking and computer programming as part of the curriculum of primary and secondary education, as described in the "national curriculum England: Study of Computer Program [27]."

The Code.org organization promotes the idea that all students should have the opportunity to learn programming. This initiative has the support of important public figures of Microsoft, Facebook and the world of technology in general [28].

Programming environments such as Scratch and ScratchJr, among others, play an essential role in this process. These programming environments allow the creation of programs that could be described as games or stories, or combination of interactive stories and games. Scratch, ScratchJr and other graphics programming environments were designed specifically for the needs of development and learning of children of 5-7, and youth 8-15 years, respectively [29], [30].

The course Computational Thinking in Schools introduces a topic of interest in society and particularly in the educational world, and in the work for research groups in cognitive science disciplines. The faculty of the course has been working for over a decade in the area of Computational Thinking [31]-[32].

\section{B. Goal and Design}

The first objective of the course is to define Computational Thinking. In the course we establish the following definition: "Computational Thinking is the process of recognizing aspects of computing in the world around us, and the application of computer tools and techniques to understand and reason about systems and processes natural and artificial."

This definition presents a holistic view of all the properties of Computational Thinking. It highlights the main ideas proposed by the principal proponents of Computational Thinking: Seymour Papert -MIT Media Lab-, and Jeannette M. Wing [33]-[36].

The second objective of the course is to use Computational Thinking through computation and the type of problems we studied in the course. Computation is performed using the Scratch programming language. The problems we propose in the course are problems known as Multiple Processes problems (MP) [37].

The course is structured into the following five modules:

1) Module 1. - Computational Thinking in School + Project Scratch Overview

2) Module 2. - Programming Language and Environment + Project Pong Game - A player

3) Module 3. - Programming Concepts and Methods + Project Pong Game - Two players

4) Module 4. - Automatic Control Module and Cybernetics + Project Driverless Car

5) Module 5. - Life Sciences + Project Butterfly Life in the Greenhouse

The first module describes the paradigm of computational 
thinking and its application in schools and in daily life. Modules 2 and 3 use Scratch to address the fundamental principles of programming languages and programming methods [38]. Modules 4 and 5 apply Computational Thinking approach to areas in our everyday environment, including automatic control, cybernetics, simulation modeling and life sciences. The goal is to better understand the natural and artificial worlds around us.

\section{Methodology}

The methodology of the course follows the guidelines of a MOOC course. This implies that the tasks of the student include: a) following a series of video lessons short, b) taking interactive quizzes, c) assessing and being assessed through testing and Peer-to-Peer (P2P) and d) participating in online forums with classmates and teachers.

The course Computational Thinking in Schools emphasizes the experience of online student learning. It highlights three important aspects of the design of the course: a) Multimedia content and Activity Scratch, b) Auto-test, c) Tasks (P2P)

The multimedia contents have been designed to illustrate in a short video a fundamental theoretical concept or a practical aspect of the Scratch project being developed in the module. The section 'Activity Scratch' leads students directly to the online environment Scratch (scratch.mit.edu) where they carry out the project described in the video.

This combination of viewing the video of the instructor and having direct access to the Scratch online environment allows students to be in control of their learning process. The student is introduced to the world of constructionism where he/she discovers the possibilities of exploring solutions in the Scratch environment.

The auto-tests allow students to evaluate their level of acquired knowledge. Self-tests have been systematically designed for each of the sections of the course. The immediate feedback provided by the auto-test indicates to the students their level of knowledge, and they will determine whether to repeat a section to review the contents, or to advance to the next section of the course.

The combination of the Auto-tests and Activity Scratch programming supports student's mastery learning [39].

The tasks Peer-to-Peer (P2P) have two steps. The first step involves the design of a Scratch project that the student must create to solve a MP problem proposed by the faculty. Students apply their knowledge to design and implement a Scratch project that will meet the proposed requirements. In each module the proposed problem is an extension of a Scratch project in the module.

The second step of the tasks $\mathrm{P} 2 \mathrm{P}$ is the assessment that the student will do of other students' projects. It provides a valuable learning experience for the student. Students in the role of evaluator acquire higher knowledge when they reason, understand and correct projects designed by other partners. To implement this assessment, the faculty provides a rubric that describes the areas to be assessed, and how to score them.

The student's learning experience is complemented with the involvement in the course community. The forum is the communication tool that enables all participants of the course, students and teachers, to be contacted for questions and or to make comments in general.

The implementation of course materials and methodologies is performed on the Miríada X platform. The platform offers the following tools to construct the course: editing tools, collaborative tools and management tools / tracking.

\section{CONCLUSION}

The recent developments in three areas of influence in the world of higher education have achieved a critical level of synergy. These areas include: online access to quality education; knowledge of how the mind works; and the use of technology to support mastery learning. As a consequence, we are experiencing a fundamental change in the method of delivery and pedagogical strategies of higher education institutions.

In this paper we review these recent events, and we analyze the forces behind them and the new strategies being introduced and explored through pilot projects.

From these ideas and developments we draw a set of conclusions that are likely to underlie major events in institutions of higher education both in the developed world, but also in the developing world, where, for the most part higher education lags in resources, experience, and pedagogical infrastructure.

Access to quality education will continue to be extended to geographical areas and demographic groups that traditionally had limited access to education. The economic model of education will be disrupted in a new market of knowledge where high quality suppliers (eminent universities) are likely to dominate.

New pedagogical methodologies will start leaving the research laboratories and will begin being introduced in the classroom. New computational approaches to knowledge acquisition and knowledge manipulation will be adopted improving the performance of students and the efficiency of the classroom.

Pilot projects, such as the project described in this paper, will constitute the field of implementation where these ideas and processes will be first integrated and then tested, evaluated and perfected before being deployed in the general education systems.

\section{REFERENCES}

[1] Coursera. (December 2015). Take the world's best courses. [Online] Available: https://www.coursera.org/

[2] edX. (December 2015). The future of online education. [Online] Available: https://www.edx.org/

[3] Udacity. (December 2015). Learn. think. do. Udacity. [Online] Available: https://www.udacity.com

[4] The New York Times. (November 2012 ). The big three, at a glance The New York Times. Education Life. [Online]. Available: http://www.nytimes.com/2012/11/04/education/edlife/the-big-three-m ooc-providers.html?ref=edlife

[5] S. Thrun and P. Norvig. (2011). Introduction to artificial intelligence. [Online]. Available: https://www.udacity.com/course/intro-to-artificial-intelligence--cs271

[6] X. Miríada. (December 2015). Nuestra filosofía en Miríada X. [Online]. Available: https://www.miriadax.net/nuestra-filosofia

[7] L. Pappan. (November 2012). "The year of the MOOC," The New York Times. Education Life. Available: 
http://www.nytimes.com/2012/11/04/education/edlife/massive-open-o nline-courses-are-multiplying-at-a-rapid-pace.html?pagewanted=all\& r $=0$

[8] Open education Europe (2013). The European MOOCs scoreboard. [Online]. http://openeducationeuropa.eu/en/open_education_scoreboard

[9] M. Duneier. (September 2012). Teaching to the world from central New Jersey. The Chronic of Higher Education. [Online]. Available: http://chronicle.com/article/Teaching-to-the-World-From/134068/

[10] G. Siemens. (July 2012). MOOCs are really a platform. Elearningspace. [Online].

Available: http://www.elearnspace.org/blog/2012/07/25/moocs-are-really-a-latfo $\mathrm{rm} /$

[11] J. Knox, S. Bayne, H. Macleod, J. Ross, and C. Sinclair. (August 2012). MOOC pedagogy: The challenges of developing for coursera. Association for Learning Technology Online Newsletter. [Online]. 28. Avalaible:

http://newsletter.alt.ac.uk/2012/08/mooc-pedagogy-the-challenges-ofdeveloping-for-coursera/

[12] T. Lewin. (November 2012). College of future could become one, come all. The New York Times. Education Life. [Online]. Available: http://www.nytimes.com/2012/11/20/education/colleges-turn-to-crow d-sourcing-courses.html?pagewanted=all\&_r=0

[13] P. Norvig. (September 2012). Helping the world to teach. Research Blog the Latest News from Research at Google. [Online]. Available: http://googleresearch.blogspot.com.es/2012/09/helping-world-to-teac h.html

[14] S. Kolowich and J. R. Young (September 2012). Stanford U. Releases new open-source online-education platform. The Chronicle of Higher Education. Wired Campus. [Online]. Available: http://chronicle.com/blogs/wiredcampus/stanford-u-releases-new-ope n-source-online-education-platform/39850

[15] J. Young. (November 2012). American Council on education may recommend some coursera offerings for college credit. The Chronicle of Higher Education. [Online]. Available: http://chronicle.com/article/MOOCs-Take-a-Major-Step/135750/

[16] J. Karpicke and J. Blunt, "Retrieval practice produces more learning than elaborative studying with concept mapping," Science, vol. 331, no. 6018, pp. 772-775, 2011.

[17] B. Bloom, "The 2 sigma problem: The search for methods of group instruction as effective as one-to-one tutoring," American Educational Research Association, vol. 13, no. 6, pp. 4-16, 1984

[18] A. Tricot and J. Sweller, "Domain-specific knowledge and why teaching generic skills does not work," Educational Psychology Review, vol. 26, issue 2, pp. 265-283, June 2014.

[19] D. C. Geary, "Educating the Evolved Mind: Conceptual Foundations for an Evolutionary Educational Psychology," Information Age Publishing, 2007. ch.1, pp. 1-100.

[20] S. Ohlsson, "The problems with problem solving: Reflections on the rise, current status, and possible future of a cognitive research paradigm," The Journal of Problem Solving, vol. 5, no.1, p.7, Fall 2012.

[21] P. Ayres and F. Paas, "Cognitive load theory: New directions and challenges," Applied Cognitive Psychology, vol. 26, no. 6, pp. 827-832, November/December 2012

[22] S. Kalyuga, "Informing: A cognitive load perspective," Informing Science: the International Journal of an Emerging Transdiscipline, vol. 14, pp. 33-45, 2011.

[23] S. Pinker, "The language instinct: The new science of language and mind," Penguin UK, 1995. vol. 7529.

[24] S. Pinker, "How the mind works," Annals of the New York Academy of Sciences, vol. 882, no. 1, pp. 119-127, 1999.

[25] M. E. Raichle, "Two views of brain function," Trends in cognitive sciences, vol. 14, no. 4, pp. 180-190, 2010.

[26] M. E. Raichle, "The brain's dark energy," Science, vol. 314, no. 5803, pp. 1249-1250, November 2006.

[27] Department for Education England. (2013). "National curriculum in England: computing programmes of study - key stages 1 and 2. Ref: DFE-00171-2013. [Online]. Available: https://www.gov.uk/government/publications/national-curriculum-inengland-computing-programmes-of-study

[28] Code.org. (December 2015). Anybody can learn. [Online]. Available: http://code.org
[29] L. P. Flannery, B. Silverman, E. R Kazakoff, M. U. Bers, P. Bontá, and M. Resnick, "Designing scratchjr: Support for early childhood learning through computer programming," in Proc. the 12th International Conference on Interaction Design and Children, pp. 1-10, 2013.

[30] M. Resnick, J. Maloney, A. Monroy-Hernández, N. Rusk, E. Eastmond, K. Brennan, and Y. Kafai, "Scratch: Programming for all," Communications of the ACM, vol. 52, no. 11, pp. 60-67, 2009.

[31] X. Basogain, F. Monroy, S. Durán, D. Rocha, M. Alvarado, M. A Olabe, and J. C. Olabe, "Fostering interdisciplinary research in computational thinking: project 3d geometry," Technology, Education and Development Conference, pp. 7072-7079, 2014.

[32] X. Basogain, M. A. Olabe, and J. C. Olabe. "Computational thinking through programming: Learning paradigm," RED Journal of Distance Education, no. 46, September 15, 2015

[33] S. Papert, Mindstorms: Children, Computers, and Powerful Ideas, New York: Basic Books, 1980.

[34] S. Papert, "Situating constructionism," in Constructionism, I. Harel and S. Papert, Eds. Norwood, NJ: Ablex, 1991. pp. 1-11.

[35] A. Disessa, Changing Minds: Computers, Learning, and Literacy, Cambridge: MIT Press, 2000.

[36] J. Wing, "Computational thinking," Communications of the ACM, vol 49, no. 3, pp. 33-36, 2006

[37] J. Olabe, X. Basogain, M. Olabe, I. Maí, and C. Castaño, "Solving math and science problems in the real world with a computational mind," Journal of New Approaches in Educational Research, vol. 3, no. 2, pp. 75-82, 2014

[38] J. Guttag, Introduction to Computation and Programming Using Python, Cambridge: MIT Press, 2013.

[39] C. L. C. Kulik, J. A. Kulik, and R. L. Bangert-Drowns, "Effectiveness of mastery learning programs: A meta-analysis," Review of educational research, vol. 60 , no. 2 , pp. $265-299,1990$



Juan Carlos Olabe is professor of Christian Brothers University (CBU), in Memphis, USA. He is a doctor engineer of telecommunications by the Polytechnic University of Madrid, and one member of the Electrical and Computer Engineering Department at CBU. He has taught courses in electromagnetic field theory, data communications, data structures, and data base design. His research activities include the areas of: a) computer network design; b) digital design; and c) computational thinking and cognitive processes.

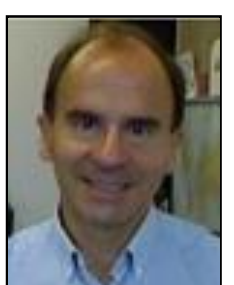

Xabier Basogain is professor of the University of the Basque Country, Euskal Herriko Unibertsitatea. $\mathrm{He}$ is doctor engineer of telecommunications by the Polytechnic University of Madrid, and one member of the Department of Engineering Systems and Automatics of the School of Engineering of Bilbao, Spain. He has taught courses in digital systems, microprocessors, digital control, modeling and simulation of discrete events, machine learning, and collaborative tools in education. His research activities include the areas of: a) soft computing and cognitive sciences to STEM; b) learning and teaching technologies applied to online education and inclusive education; c) augmented and virtual reality with mobile technologies

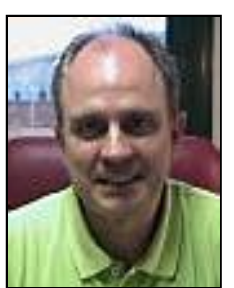

Miguel Ángel Olabe is professor of the University of the Basque Country, Euskal Herriko Unibertsitatea. $\mathrm{He}$ is doctor industrial by the University of the Basque Country, and one member of the Department of Engineering Communications of the School of Engineering of Bilbao, Spain. He has taught courses in computer structure and architecture, programming, modeling and simulation of networks, multimedia services, and creation and distribution of multimedia content in education. His research activities include the areas of: a) soft computing and cognitive sciences to STEM; and b) learning and teaching technologies applied to online education and inclusive education. 